\title{
Residential House Solar Modelling through Electrical Energy Audit
}

\author{
K.Ganesh ${ }^{1} \mid$ K.Kanimozhi ${ }^{2}$
}

${ }^{1}$ Assistant Professor, Department of EEE, Nadar Saraswathi College of Engineering \&Technology,Theni

${ }^{2}$ Professor, Department of EEE, Sethu Institute of Technology, Kariapatti

To Cite this Article

K.Ganesh and K.Kanimozhi, "Residential House Solar Modelling through Electrical Energy Audit", International Journal for Modern Trends in Science and Technology, Vol. 07, Issue 01, January 2021, pp.- 121-127.

Article Info

Received on 11-November-2020, Revised on 02-December-2020, Accepted on 08-December-2020, Published on 17-January-2021.

\section{ABSTRACT}

Reducing electricity consumption in commercial buildings is important in addressing the growing concerns of global warming, atmospheric quality and energy security. Energy audit is a proven effective measure for energy savings through identification of energy management opportunities for improvement by means of buildings. The energy study of various sector of commercial, industrial and residential area indicates that 5 to $20 \%$ of the energy can be saved. The power auditing is done in a residential home and concluded with suitable recommendations on solar modeling with ETAP tocutt off electricity bill resonablly. From our Energy audit we prove that we can save upto 2358 units yearly.

KEYWORDS : Energy Audit, Energy Management and Energy Saving.

\section{INTRODUCTION}

ThisEnergy is the ability to do work and work is the transfer of one form of energy. Energy exists in several forms such as heat, kinetic, light, electrical energy. The entire progress of a country is dependent only on Energy. Recent days, energy saving has become essential rather than electricity generation. If we think for potential cost saving in each of the components (energy, material, employees), energy would invariably emerge at the top, so efficient use of energy and its conservation is the least cost option in any strategy. The energy demand is increasing because of the increasing population in country hence; country is facing peak power and average electricity shortage of $12 \%$ and $7 \%$ respectively. To satisfy the energy needs of Tamil Nadu, TNEB has a total installed capacity of 20103MW [1] which include of all, State Government, Central Government, Independent power producer and renewable power generation. To meet the ever increasing energy demand, TNEB has proposed a number of next generation projects to be constructed. The per capita consumption of Tamil Nadu is 1000 units. It was found from the survey that India is the world's fifth largest electricity generator but still there are many places in India which are in dark and they are very far away from the term "electricity". Soit's the time for energy saving. It is possible only byeffective Energy Audit and Energymanagement.

\section{DATA OBSERVATION}

An energy audit is an inspection, survey and analysis of energy flows for energy conservation in a building, processtoreduce the amount of energy input into the system without negatively affecting the output. It shows where the power consumption is more in the given system. It can also be called as 
controlling of the power to avoid losses for maximize efficiency. Energy savings of the order of 5 to $20 \% \quad$ are possiblebyoptimizinguseofEnergywithbetter housekeeping, low cost retrofitting measures and use of Energy efficient equipment at the time of replacement, renovation or up gradation. Energy Audit will help to understand more about the ways energy and fuel are used in any industry, and help in identifying the areas where waste can occur and where scope for improvement exists. The Energy Audit would give a positive orientation to the energy cost reduction, preventive maintenance and quality control programs which are vital for production and utility activities. The audit conducted in the residential home with the recommended procedure and collected all the data from the existinglayout.

\section{PROCEDURE}

- Record the phase, line to line voltage of thehouse.

- Check the status of earthing and measure earth voltage.

- Collect the data with respect to data sheetformat.

- Draw the single line diagram of thehouse.

- Collect the energy meter tarrifsurvey for fiveyears.

- Collect the data for daily load curve.

- Real time load collection, voltage, current and power factor.

- Collect the answers for surveyquestions.

- Energy wastageaudit.

- Observation for regular fault occur in ahouse.

- Observation of safetymeasures.

- Preparation of energy audit report with suitable recommendation.

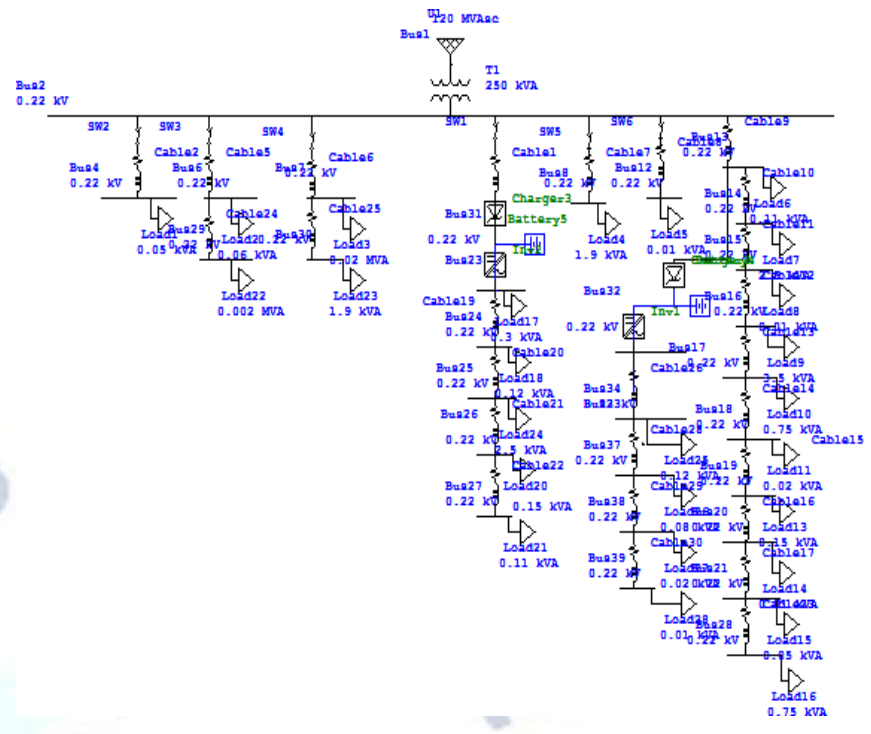

Fig.1 Existing equipment layout

\section{Power consumption Chart:}

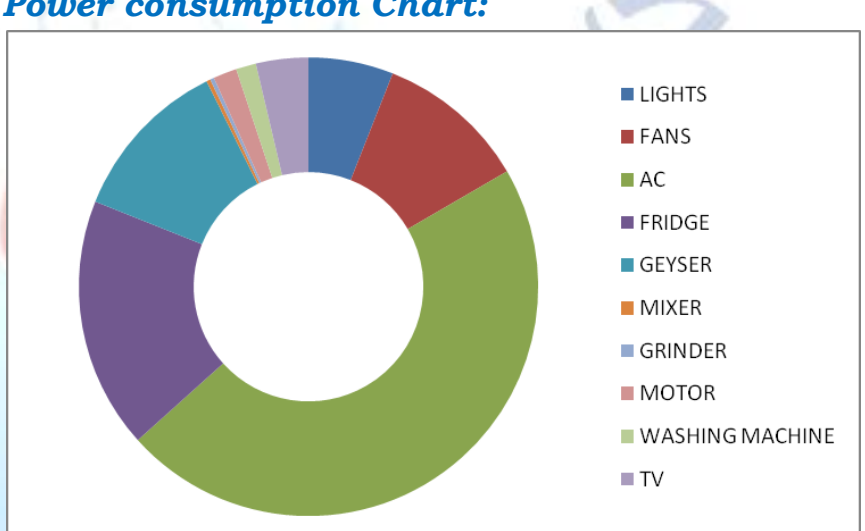

Fig.2 Total Power consumptionchart

The above graph explains about power consumption of each equipment.

From the pie chart we can see the maximum power is being used by air conditioner, fridge, geyser, fans, lights and others

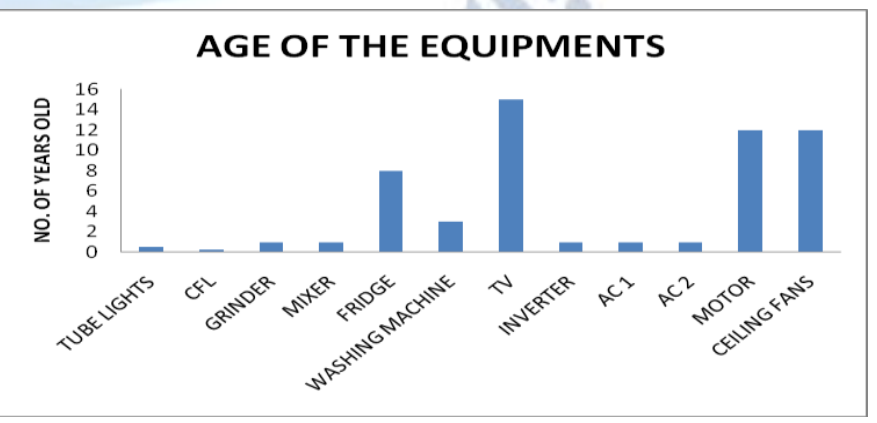

Fig.3 Age of Equipments

Fig. 3 shows that the age of equipment which is used in the house. It gives an idea about the 
performance and power consumption of the equipment. It's also giving some rough idea about past performance of the equipment. According to the graph, we show that TV, fans and motor are the most oldequipments of the house.

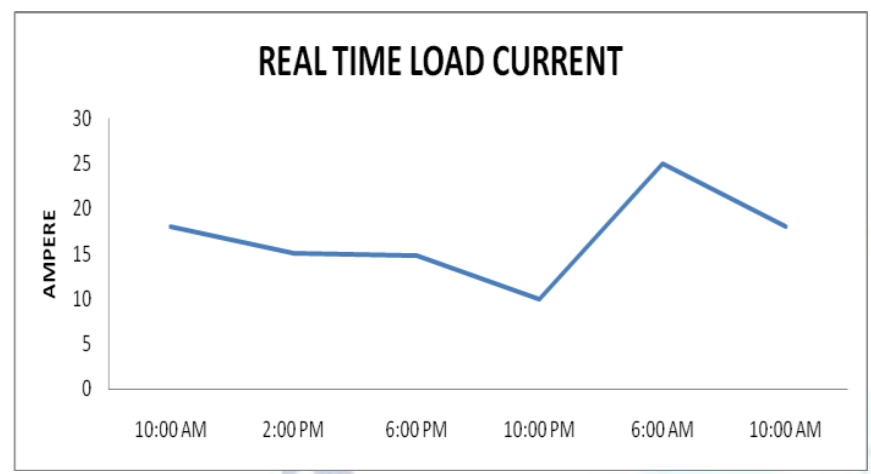

Fig.4 Real time load current

Fig. 4 represents the real time load current between specific time interval.The real time load curve reading shows when specific electrical and electronics items are turned on. From the graph we came to know that current consumption between 6:00 am to $10: 00$ am is maximum.. The major current reading was obtained from AC, Grinder, fans and washingmachine.

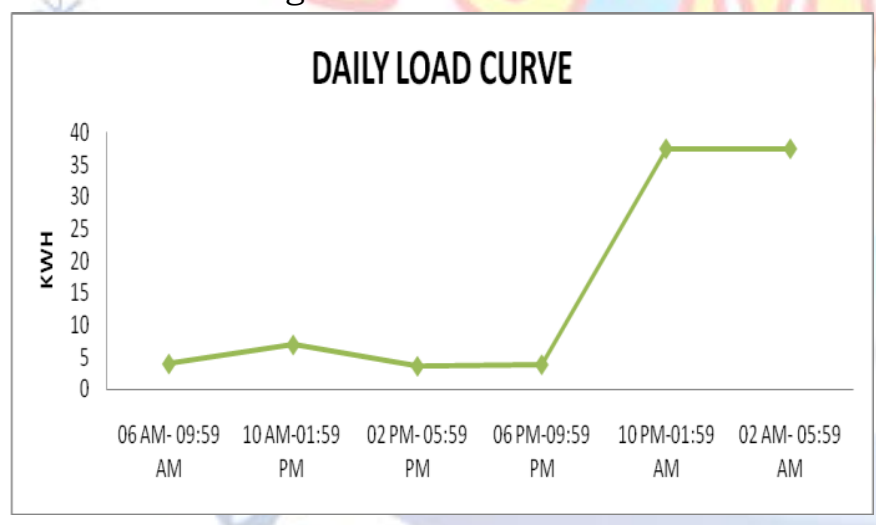

Fig. 5 Daily Load Curve

Fig. 5 indicates the daily load curve that is the daily power consumption between specific interval of time. From the graph we came to know that the power consumption is maximum between $10 \mathrm{pm}$ to $6 \mathrm{am}$. The power consumption is maximum due the continous use of the AC's, fans and freeze.

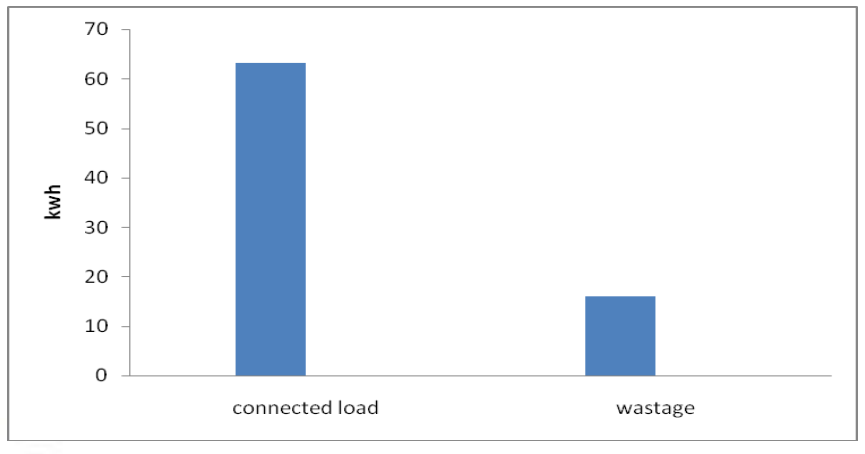

Fig. 6 wastage Comparision

From the graph we can see that the connected load is $63.09 \mathrm{kwh}$ and wastage is $10.93 \mathrm{kwh}$.

\section{RECOMMENDATION}

According to our team we have given three recommendations after doing energy audit. First is "WithoutInvestment", second is "With investment", and third is microgridwithsolarimplementation

\section{A.Recommendation Withoutinvestment}

- RY B does not have a balanced load. It is found that in $\mathrm{R}=9.109 \mathrm{~A}, \mathrm{Y}=.707 \mathrm{~A}$ and $\mathrm{B}=2.756 \mathrm{~A}$ so our first recommendation is to change the unbalanced load into a balanced one, so that we can get good inputvoltage.

- We found that the gap between refrigerator and the wall is very close, which reduces the efficiency of the refrigerator and it also consumes more power. So we recommend the house owner to maintain properdistance.

- Utenstils made up of steel should be avoided inside therefrigerator.

- Never use fans with air conditioners which results in unusual use ofpower.

- Close the door when using airconditioners.

B. Recommendation WithLED

It is recommended to use LED instead of flourscent light and CFL. According to the survey the there were about 8 tube lights and 8 $\mathrm{cfl}$ and 2 outside lights presently working. So by replacing them with LED a considerable amount of the power can be saved.

TABLEI. LED CONVERSION CALCULATION CHART

\begin{tabular}{|c|c|}
\hline \multicolumn{2}{|c|}{ Present energy uses } \\
\hline $\begin{array}{c}\text { Total number of florescent } \\
\text { light }=\end{array}$ & 8 \\
\hline
\end{tabular}




\begin{tabular}{|c|c|}
\hline Total power in watts $=$ & $320 w$ \\
\hline Total units consumed= & 817.6 unit/yr \\
\hline Cost annually= & Rs. 2452.8 \\
\hline \multicolumn{2}{|c|}{ If tube light(8) replaced by LED's } \\
\hline Total number of LED's= & 8 \\
\hline Total number of watts $=$ & $160 w$ \\
\hline $\begin{array}{l}\text { Total units consumed in a } \\
\text { year }=\end{array}$ & 408.8Units/year \\
\hline Cost annually= & Rs. 1226.4 \\
\hline Savimg in units per year & 408.8 units \\
\hline Saving in cost per year & Rs. 1226.4 \\
\hline
\end{tabular}

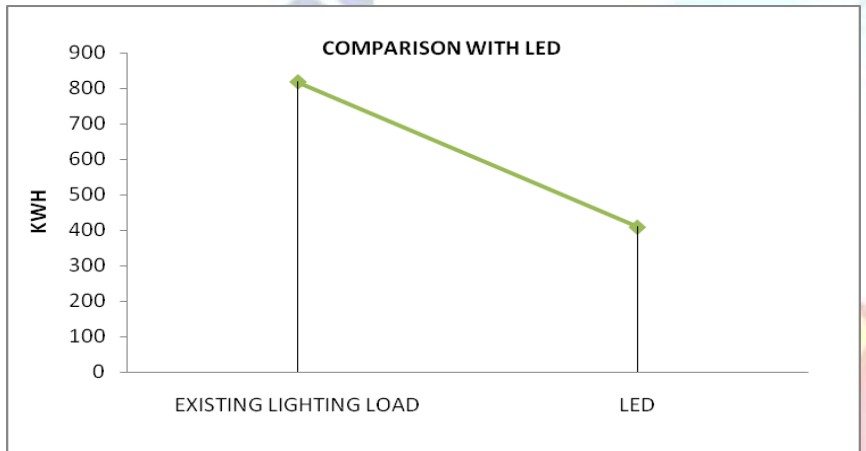

Fig. 7 Comparidion to LED with respect to units

The above graph shows the comparison of led with existing lighting loads. By using led $408.8 \mathrm{kwh}$ of the power can be saved.

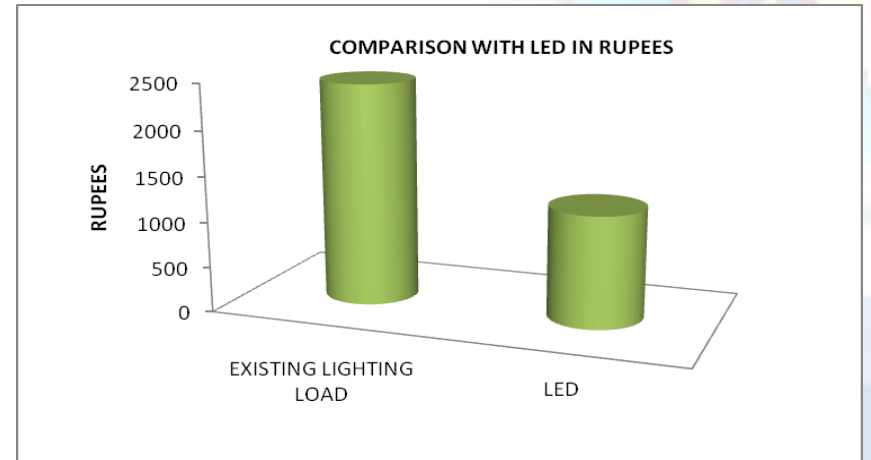

Fig.8 Comparrision to LED with respect to Rupees

the above graph shows comparison of the lighting loads in rupees. From the above graph we came to know that a considerable amout of Rs. 1226.4 can be saved.

C. Recommendation With inverterAC

\section{TABLE II. A.C CONVERSION CALCULATION CHART}

\begin{tabular}{|c|l|}
\hline Present energy uses \\
\hline Total number of existed $\mathrm{AC}=$ & \\
\hline Total power in watts $=$ & \\
\hline Total units consumed $=$ & \\
\hline
\end{tabular}

\begin{tabular}{|c|c|}
\hline Cost annually $=$ & Rs.23490 \\
\hline \multicolumn{2}{|c|}{ If existing AC are(2) replaced by star rated AC } \\
\hline tal number of star rated AC $=$ & 2 \\
\hline Total number of watts $=$ & \\
\hline $\begin{array}{c}\text { Total units consumed in a } \\
\text { year }=\end{array}$ & \\
\hline Cost annually $=$ & \\
\hline Savimg in units per year & Rs.10530 \\
\hline Saving in cost per year & \\
\hline
\end{tabular}

\section{POWER CONSUMPTION OF STAR RATED A.C}

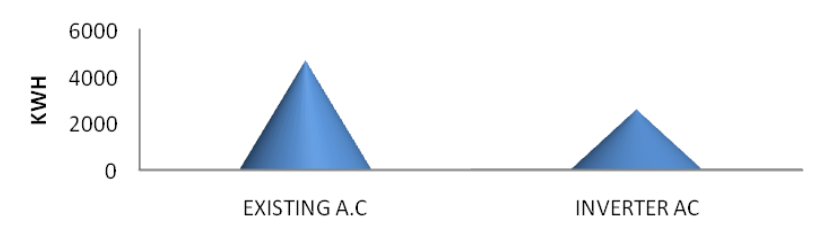

Fig. 9 Star rated $A C$ power comparission in units

According to the survey we came to know that there were about $2 \mathrm{AC}$ installed of total 4350 watts and consumes about 4698uits per year which is a huge amount which can be seen in fig 9 . So by using inverter AC's a considerable amount of 1950 units of power can besaved.

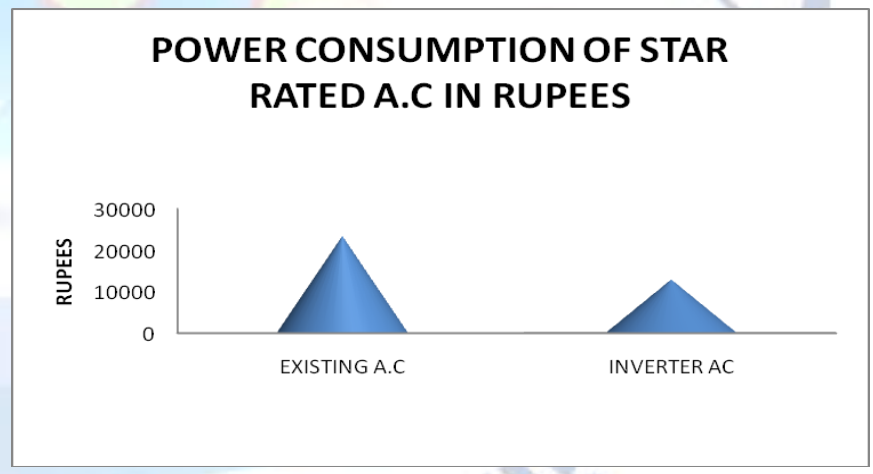

Fig.10 Star rated AC power comparission in rupees

Fig 10 shows the power consumption in rupees for star rated AC's. A sum of Rs 10530 can be saved by using inverter $\mathrm{AC}$ 's.

\section{Recommendation With efficientgyser}

From the table we came to know that there were about 2 gysers installed in the home. Each of which consumes about 3500 watts of power. So a by recommending efficient gyser a considerable amount of power can besaved. 
TABLEIII GEYSER CONVERSION CALCULATION CHART

\begin{tabular}{|c|c|}
\hline \multicolumn{2}{|c|}{ Present energy uses } \\
\hline Total number of existed gyser= & 2 \\
\hline Total power in watts= & $7000 \mathrm{w}$ \\
\hline Total units consumed $=$ & Rs.7664 \\
\hline Cost annually= & \\
\hline If all existing Geyser are(3) replaced by star rated geyser \\
\hline Total number of gyser= \\
\hline Total number of watts $=$ & 3600 \\
\hline Total units consumed in a & 492.75 units per year \\
\hline year= & \\
\hline Cost annually= & Rs.1231.87 \\
\hline Savimg in units per year & 3400 units \\
\hline Saving in cost per year & Rs.6432.13 \\
\hline
\end{tabular}

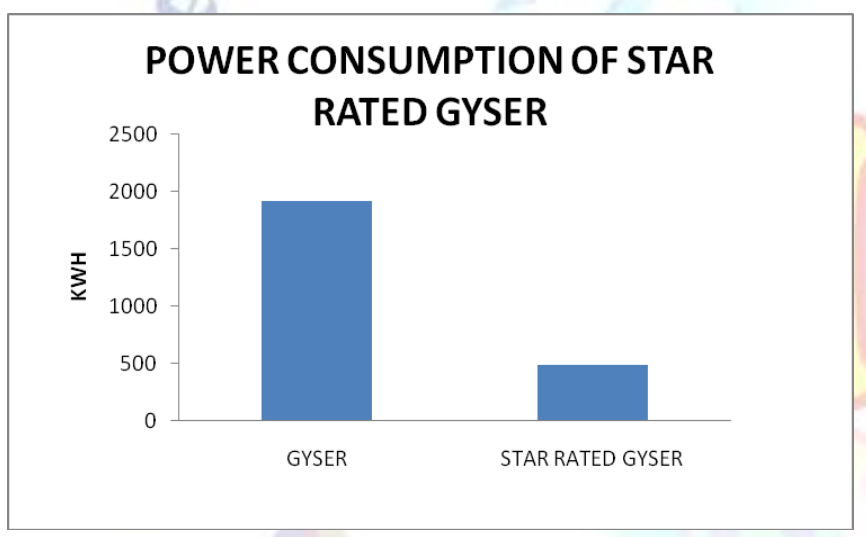

Fig. 11 Star rated Gyser power comparission in units

From the fig. 11 we cocclude that the power consumption of the installed gyser is $1916 \mathrm{kwh}$. The power consumption of the efficient gyser is 492.75. so about $1423.25 \mathrm{kwh}$ can besaved.

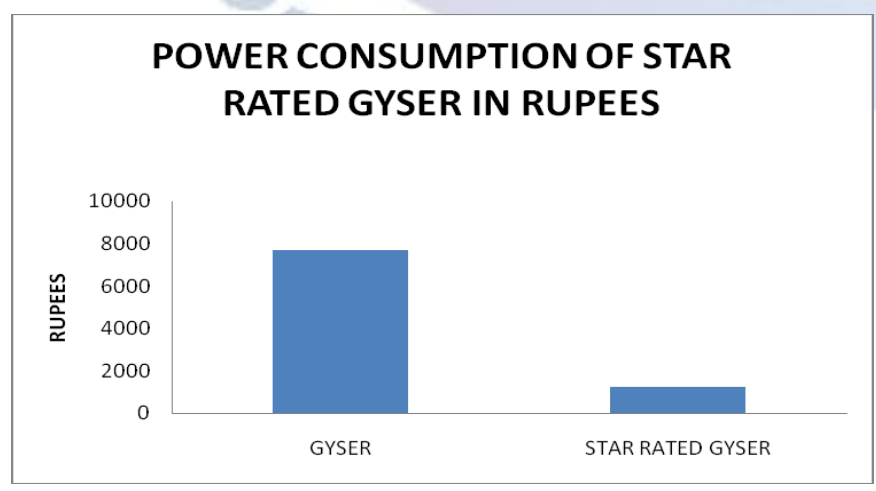

Fig.12 Star rated Gyser power comparission in rupees
From the above graph we can see that the existing gyser consumes about Rs. 7664 and the star rated gyser consumes about Rs.1231.87. so by recommending star rated gyser a sum of Rs. 6432 can be saved.

E. Recommendation With star ratedfans

\section{TABLEI . FANS CONVERSION CALCULATION} CHART

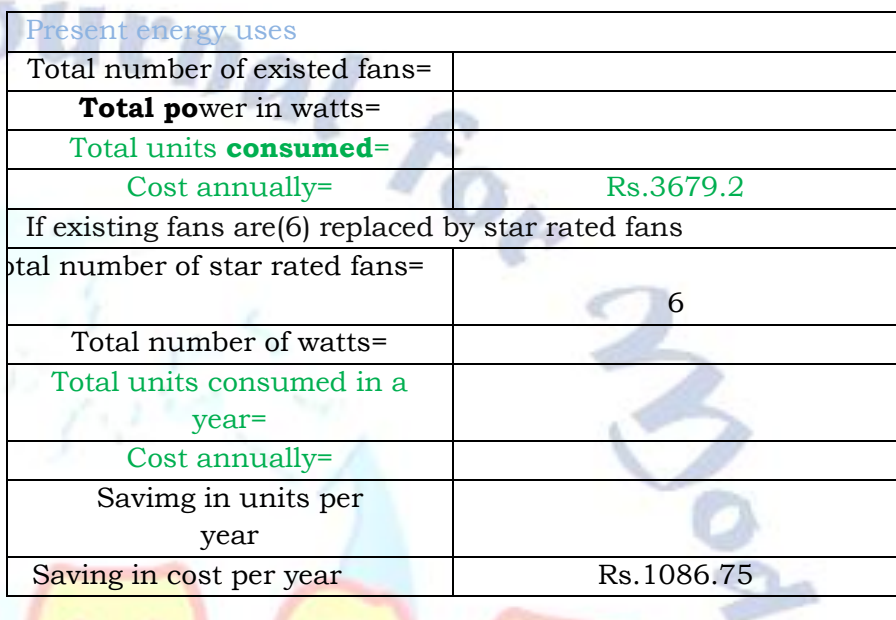

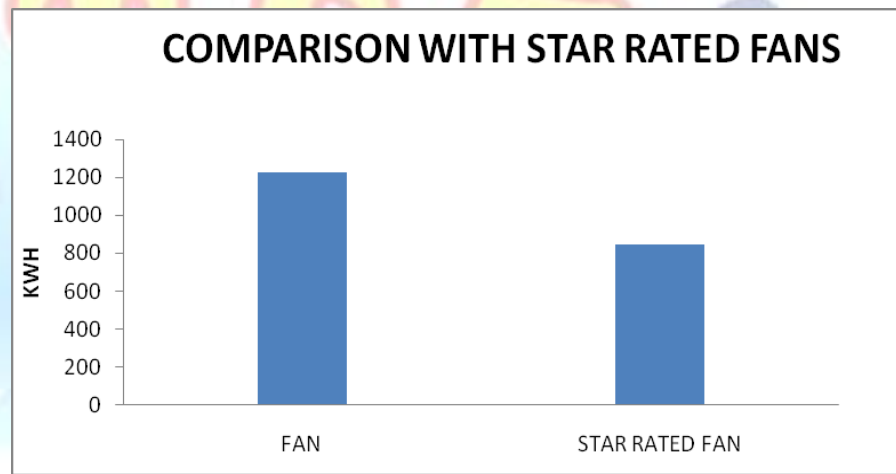

Fig.13 Star rated Fans power comparission in units

From figure 13 we conclude that the exising fan consumes $1226.4 \mathrm{kwh}$. So by recommending star rated fans the consumption reduces to 843.15 $\mathrm{kwh}$. A sum of $383.25 \mathrm{kwh}$ can be saved per year

\section{COMPARISON WITH STAR RATED FANS IN...}

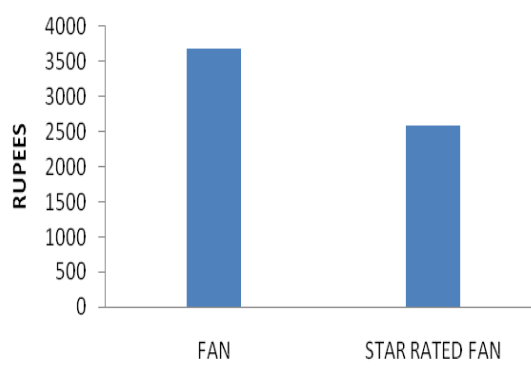

Fig.14 Star rated Fans power comparission in rupees 
From the fig14 we can see that the present power consumption in rupees is Rs 3679.2 and with star rated fans is Rs.2592.45. so Rs 1086.75 can be saved.

\section{F. Recommendation With rearrangedloads}

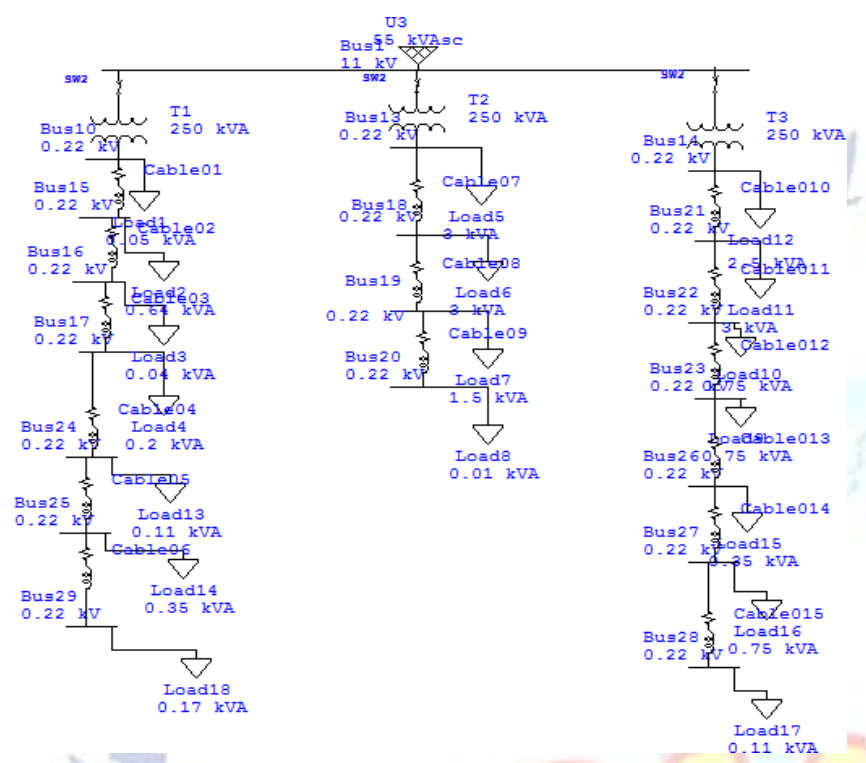

Fig.15 Rearranged load structures

In fig. 15 it is recommended to rearrange the loads equally in three phases. this will increase the voltage rating of each of the bus bar.

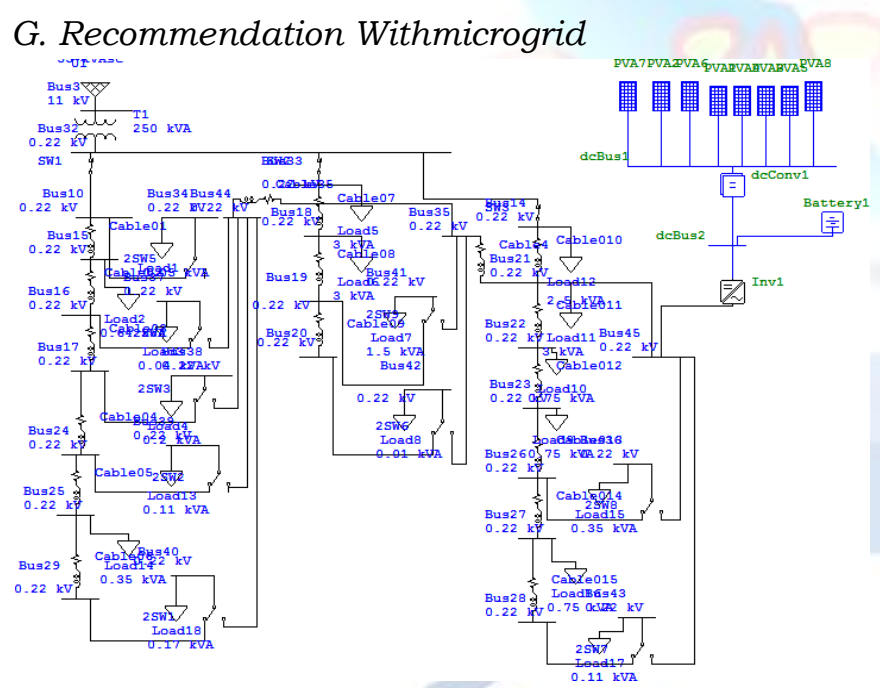

Fig.16 Recommendation with micro grid

Microgrid is recommend in the flat for the lighting loads and fans. Solar power is used for the microgrid implementation. It is recommended to use $1.5 \mathrm{KW}$ solar panel for microgrid.

\section{CONCLUSION}

After successfully completion of auditing at residential house we came to know there are three things that consumes more power that is lighting,cooling and heating. lights are replaced wt. Using of LED lights instead of CFL tubes, with LED lights star rated Ac's instead of normal one and wall fans. Using $1 E D$ lights 408.8 units can be saved yearly and by using star rated A.C1950 units can be saved yearly. Energy audit process must be carried out accurately enough to identify and quantify energy cost saving that are likely to be realized through investment in Energy savingmeasures.

\section{REFERENCES:}

[1] M.Bharath Kumar Singh, K.Ganesh, DeepakKumar Soni, Asha Mandal, Avinash Kumar, Awanish Kumar K. Kannan and L. Ramesh "University laboratory power audit study with conservation recommendation." 2016 International Conference on Electrical, Electronics, and Optimization Techniques (ICEEOT).

[2] Kaddari, M., El Mouden, M., Hajjaji, A., \&.Semlali, A.” Reducing energy consumption by energy management and energy audits in the pumping stations." 2018 Renewable Energies, Power Systems \& Green Inclusive Economy(REPS-GIE).

[3] Simelane, S., Isaac, N., Duma, T., \& Chowdhury Daniel, S. "Energy Efficiency Audits - A Strive for Energy Autonomy." 2018 IEEE PES/IAS PowerAfrica.

[4] Aadithya G. "Application of energy value stream mapping as auditing tool for non-value added industrial energy management." 2016 3rd International Conference on Electrical Energy Systems(ICEES)

[5] Saravanakumar, R., Chetan, N., Chakaravarthy, P., Karthickkeyan, Rakesh, S., \&Ramkiran.” M Energy audit report." 2017 Third International Conference on Advances in Electrical, Electronics, Information, Communication and Bio-Informatics(AEEICB).

[6] "The impact of ETAP in residential house electrical energy audit” byAwanishkumar,sashiranjan, M. Bharathkumarsingh, $\mathrm{P}$ riyankakumari.

[7] S.U Kulkarni and kalpana pail "Energy audit of an industrial unit-A case Study" International Journal of emerging science and engineering, Volume-2, Issue1 ,November 2013

[8] ARUN KUMAR AHUJA "Energy Audit Of IIT- Roorkee Campus "in January2010.

[9] Malikatsingh, gurpreet Singh and haarmandeep Singh "Energy audit a case study to reduce the lightingcost"

[10] Asian journal of computer science andinformation technology,2012,PP 119-122

[11] Mukesh K Saini S.Chatterjee and Lini Mathew, "Energy audit of an industry", International Journal o scientific \& Technology Research Volume 3, Issue 12, 2014

[12] Mehul Kumar J Panchal, Ved Vyas Dwivedi and RajendraAparnath, "The case study of energyconservation\& audit in Industry sector" , International Journal of Engineering And Computer Science, Volume 3 Issue 4 April,2014.

[13] "Energy Audit: A Case Study of Hostel Building" Malik Sameeullah, Jitendra Kumar, KanhaiyaLal, JagdishChander.

[14] "IIT Kanpur Halls of Residence energy audit" byanandkumarmishra.Keerthi Jain, N, Kishore Kumar, Ramesh, L and MadhusudhanaRaju, (2015), "Comparatative Analysis of Residential Houses for Effective 
Reduction in Power Demand" Research India Publications, International Journal of Applied Engineering Research, Volume 10, Number 6, PP 5489 to5494.

[15] Awanish Kumar, Abhishek Raj, Ajitkumaryadav and Ramesh, L, (2015) "Energy Audit for a Residential House with Considerable Recommentation for Implementation" International Journal of Applied EngineeringResearch, Vol. 10,No.20, PP 15537-15541

[16] MadhusudhanaRaju, Ramesh, L and Balamurugan, (2015), "Residential House Energy Conservation Analysis through Proposed Package" Research India Publications, International Journal of Applied Engineering Research, Volume 10, Number 6, PP 5526 to5531.

[17] Keerthijain, K, Kishore Kumar, N, Ramesh, L, and MadhusudhanaRaju, M, (2014), "An Analysis to Save Electrical Energy in a Residential House" International Journal of Engineering Sciences, Vol:6(2), PP59-66

[18] Awanishkumar, M.Thanigivelu, R.Yogaraj and L.Ramesh (2015), "The Impact of ETAP in Residential House Electrical Energy Audit", Elsevier Proceeding of International Conference on Smart Grid Technologies August2015.

[19] Keerthi Jain, K, Kishore Kumar, N, Muralikrishanan and Ramesh,L, (2015), "An Analysis to Save Electrical Energy in a Residential House Using ETAP" Published in Springer Proceeding ofInternational Conference on Communication, Computing and Power Technologies (ICCCPT-2015) -April 2015 -Chennai

[20] Keerthi Jain, K, Kishore Kumar, N, Muralikrishanan and Ramesh,L, (2015), "An Analysis to Save Electrical Energy in a Residential House Using ETAP" Published in Springer Proceeding ofInternational Conference on Communication, Computing and Power Technologies (ICCCPT-2015) -April 2015 -Chennai.

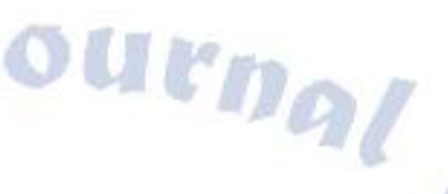

